\title{
Accepting labels in two languages: Relationships with exposure and language awareness
}

\author{
Dolly P. Rojo and Catharine H. Echols \\ drojo@utexas.edu \\ UNIVERSITY OF TEXAS AT AUSTIN
}

\begin{abstract}
In a study investigating how exposure to a non-native language influences acceptance of vocabulary from that language, English-speaking children heard novel labels from Spanish and English speakers. Children were categorized, based on their exposure to and fluency in Spanish, as minimal exposure, moderate exposure, or bilingual. Moderate-exposure children accepted labels from both speakers more frequently than minimal exposure children, and were statistically equivalent to bilinguals. Additionally, children's language awareness was assessed; it was associated both with their willingness to accept labels across two languages and with the amount of exposure to Spanish.
\end{abstract}

Key words: bilingualism, children, preschool, language development, novel labels

\section{Résumé}

Dans une étude portant sur les effets de l'exposition à une langue seconde sur l'acquisition du vocabulaire, des enfants anglophones ont entendu de nouveaux termes produits par des locuteurs d'anglais et d'espagnol. Les enfants ont été classés en fonction de leur niveau d'exposition à l'espagnol et de leur maîtrise de cette langue en trois catégories : enfants à exposition minimale, enfants à exposition modérée et enfants bilingues. Les enfants à exposition modérée ont accepté les termes des deux groupes de locuteurs plus fréquemment que les enfants à exposition minimale, et étaient statistiquement équivalents aux bilingues. Le niveau de sensibilisation à la langue a aussi été évalué chez les enfants. Il était associé à leur volonté d'accepter les termes dans les deux langues ainsi qu'à leur degré d'exposition à l'espagnol.

Mots-clés : bilinguisme, enfants, âge préscolaire, développement langagier, nouveaux termes 


\section{Introduction}

Bilingual education programs are becoming increasingly popular in the United States of America, particularly in states like California and Texas. Originally, these programs were intended to serve "limited English proficient" children (Stewner-Manzanares, 1988). Increasingly, however, these programs are also enabling monolingual English-speaking children to learn a second language.

One of the reasons for the increased interest in dual-language programs is a change in perspective on bilingualism. Although acquiring two languages as a young child was once considered a disadvantage and a potential deterrent to developing language proficiently (Fernandez, 2006), recent research has shown that there are cognitive advantages to being bilingual. Evidence has been found for cognitive flexibility not only in the context of language (e.g., the ability to distinguish sentences that are grammatically correct but semantically incorrect; Bialytok, 2001), but also in other domains (Bialystok, 1999; Bialystok \& Feng, 2009).

Given the increase in young children's enrollment in dual-language programs, it would be valuable to investigate children's conceptual processes when hearing a non-native language. This has been largely understudied. In particular, little research has focussed on children's willingness to accept words from non-native speakers. Furthermore, the process that occurs when monolingual children encounter a non-native speaker is likely very different from that of bilingual children.

\section{Hearing a non-native speaker}

The experience of learning from a non-native speaker, as in these dual-language programs, may be very different for English-speaking children than for bilingual children. Several studies have found that monolingual children are reluctant to accept that an object can have more than one label across two languages (e.g., Au \& Glusman, 1990). Bilingual children have shown less reluctance to do so, and more readily accept that novel objects can have more than one label within or across different languages (e.g., Akhtar, Menjivar, Hoicka, \& Sabbagh, 2012; Au \& Glusman, 1990; Davidson \& Tell, 2005). Still, some work with monolingual children suggests that, in specific situations, they are willing to accept labels from non-native languages. For example, when the experimenter emphasized that the novel label was in a different language, monolingual children were more likely to accept that new word (Au \& Glusman, 1990) than when the origin of the label was less salient. Proficiency with their native language may be another factor affecting monolingual children's willingness to accept labels from a non-native speaker. Koenig and Woodward (2012) provide evidence that a large vocabulary in toddlers' native language is associated 
with their willingness to endorse labels in a non-native language. These findings suggest that proficiency with just one language may increase children's willingness to accept two labels in different languages for a single object.

\section{Language awareness}

Being willing to accept labels from different languages could require that children first reflect on the fact that they are speakers of a language (or of more than one language). This metalinguistic awareness has been referred to as Language Awareness. Language awareness is "the ability to reflect on languages and to verbalize that reflection" (cited in Sá \& Melo, 2007, p. 93). Bilingualism may be associated with language awareness (Sá \& Melo, 2007). Indeed, it has been associated with such metalinguistic skills as recognizing that an object can be disassociated from its label (e.g., Cummins, 1978; Bialystok, 1988) and separating the syntactic structure of a phrase from its meaning (e.g., Bialystok \& Majumder, 1998). To the degree that exposure to a non-native language fosters metalinguistic awareness, those language awareness skills conceivably could promote accepting labels from speakers of two languages.

One means of revealing language awareness comes from studies with immigrant children that have used drawings or "visual" narratives (e.g., Martin, 2012; Melo-Pfeifer, 2015) to gain insight into language identity. Krumm and Jenkins (2001), among the first to implement this method, presented elementaryaged children with empty silhouettes and then asked them to complete the silhouettes with colours representing the languages that they know. Martin (2012) provided 10- and 14-year-old children with a similar task, but also first asked children about their language experiences (e.g., what languages they are learning, what languages they prefer, etc.),

Taking a slightly different approach, Melo-Pfeifer (2015) provided children with blank pages, and simply asked them to "draw [themselves] using the languages [they] know" (p. 202). Melo-Pfeifer then categorized the content of children's drawings based on the children's knowledge of the languages they speak, or how they identify as speakers of these languages. These studies typically were exploring immigrant children's language identities, but because the drawing tasks ask children to reflect on their language(s) and how they use them, this task might also be valuable for assessing language awareness.

\section{Exposure to non-native languages}

Most past research has taken a dichotomous approach in comparing bilingual children and monolingual children when looking at label-learning. In many communities, however, children who are not bilingual nonetheless may have substantial exposure to non-native languages. This raises the question of exposure effects on willingness to accept labels from different languages. 
It is possible that, as a result of greater amount of exposure to a second language, children begin to appreciate that there can be two different labels for the same object across different languages. As a result, children with substantial amounts of exposure, despite not being fluent in a second language, may show greater willingness to accept labels from two different speakers than children with limited exposure to a non-native language.

\section{Current study}

The study extended beyond past research by considering variability of exposure as a predictor for children's label endorsements. In this study, we assessed the variability of monolingual English-speaking children's exposure to a nonEnglish language and how this variability in exposure might affect children's openness towards labels provided by a non-English speaker. We also explored the association between exposure and expressions of language awareness as well as the association between language awareness and children's willingness to endorse novel labels.

\section{Method}

\section{Overview of study}

Children were grouped by the amount of exposure to Spanish, as described by parents; there was a Spanish-English bilingual group and two monolingual groups in which children were minimally exposed to Spanish, or more substantially exposed.

For the primary task, children watched a short video of two females introducing several objects in English and Spanish, including two novel items, and were asked to endorse either or both of the labels provided for each novel object. Children also completed a questionnaire consisting of queries about their experiences with non-native languages, and were additionally assessed on their receptive vocabulary skills in English and Spanish. Finally, they completed a drawing activity similar to that of Martin (2012), as a measure of language awareness.

\section{Participants}

Participants were 98 4- to 6-year-old ( $M=5.23, S D=11.4$ months) Englishspeaking children from a diverse, urban community in central Texas, United States. Some children were excluded from individual analyses due to experimental error or missing data and these exclusions are described for each measure. Based on parent identification, $71 \%$ of child participants were white or European, $15 \%$ were mixed, $13 \%$ were Asian, and $1 \%$ were American Indian or Alaska native; $38 \%$ of these children were also identified as Hispanic. All 
participants were native speakers of English; 16 were also proficient in Spanish, and many had moderate amounts of exposure to Spanish. The language exposure of participants is described more fully below.

\section{Materials}

\section{Objects and labels}

Three familiar objects (a toy dinosaur, a toy train, and a baby doll) as well as two novel, abstract-looking objects were used. Familiar objects were selected so that their labels are cognates in Spanish and English. Cognates were used so that monolingual children understood that the Spanish speaker was labelling accurately. Novel object labels were constructed to be phonologically consistent with the pertinent language. English labels for familiar objects consisted of the following: Train, Baby, Dinosaur. Spanish labels for familiar objects consisted of the following: Tren, Bebe, Dinosaurio. English labels for novel objects consisted of the following: Wibber, Rompet. Spanish labels for novel objects consisted of the following: Bufo, Chisa.

\section{Video stimulus}

The video showed two female speakers labelling each object. The two actresses were native speakers of both English and Spanish, and spoke each language with a native accent. The video began with each speaker introducing herself as either Mary (English speaker) or Ana (Spanish speaker), after which each speaker labelled the first familiar object. Two additional familiar trials followed, after which the test trials were presented in the same manner. Each actress consistently spoke one language throughout the experiment, but played the role, in different videos, of both Mary and Ana. The actress playing each role was counterbalanced between participants, and the order of languages was also counterbalanced.

\section{Peabody Picture Vocabulary Test (PPVT)}

The PPVT-III (Version 3) with Form IIIA (Dunn \& Dunn, 1997) is an age- and grade-based standardized vocabulary test $(M=100, S D=15)$ for children ages two to adults 90+ years old, that assesses vocabulary in American English.

\section{Test de Vocabulario en Imágenes Peabody (TVIP)}

This task is also published by the American Guidance Service (Dunn \& Dunn, 1986), is very similar to and is based on the PPVT-R (the second version of the PPVT), but is conducted in and assesses vocabulary in Mexican Spanish. 


\section{Language background questionnaire for parents}

In order to assess children's exposure to and knowledge of languages other than English, parents completed several tables and open-ended questions about the frequency of the languages their children hear. This measure was developed specifically for the present study. Parents were asked which languages the child is exposed to, after which they specified the number of hours per week that the child hears these languages. In addition, parents were asked to rate their child's proficiency in each of the languages to which they are exposed (i.e., knowing only a few words in that language, knowing several words and phrases, or knowing the language fluently).

Children with three or fewer hours per week of exposure to Spanish were categorized into the Exposure-Minus group. Children with more than three hours per week of exposure, but not rated by their parent as being fluent in Spanish, were categorized into the Exposure-Plus group. Children fluent in Spanish (i.e., described by a parent as understanding and speaking Spanish fluently, or as being fluent in it), were categorized into the Bilingual group. The cut-off of three hours per week was selected because it resulted in roughly equivalent numbers of children in the Exposure-Minus and Exposure-Plus groups, and because it excluded from the Exposure-Plus category those monolingual children who heard small amounts of Spanish through short in-class lessons at school.

Although the language of interest for this study was Spanish, parents also completed questionnaires for any additional languages to which the child was exposed. All parents listed Spanish as a language of exposure, but 26 parents listed languages in addition to Spanish (Chinese, Japanese, German, Italian, French, Urdu, Hebrew, Tagalog, ASL, Vietnamese, Hindi, and Farsi). In 21 of these cases, however, exposure to these languages was less than two hours per week. For this reason, and given the lack of receptive vocabulary measures for these other languages as well as the lack of comparison to children fluent in these other languages, exposure to additional languages was not used in assigning children to exposure categories.

\section{Child Language Questionnaire (CLQ)}

This was a series of open-ended questions, designed specifically for the present study, regarding the child's experience with language(s) in the home and at school (if applicable). Other questions addressed potential favoritism between known languages, potential hesitancy to use one or more language in particular settings, whether children speak to peers in a non-English language, and also a question on children's knowledge of the term "bilingual". These questions were included to address exposure to non-English languages that the par- 
ents may not have been aware of, as well as to assess children's reflections about language.

\section{Language Silhouette activity}

For this task, we used a black-and-white silhouette of a person, designed to assess language awareness. A female silhouette (longer hair and wearing a dress) was given to female children and a male (shorter hair and pants) to males. The instructions were very similar to those given in Martin (2012). Children were told: "Here's what we're going to colour, now let me tell you how to play. You have to pick one colour for each language that you know, and then colour this [point to silhouette] with what you chose. Got that? You pick one colour for each language that you speak, and then colour this [point to silhouette] with what you chose."

Instructions were repeated twice at the beginning and, if the child asked questions while drawing, the same instructions were repeated - no further details were provided. After each child completed the drawing, the researcher asked three follow-up questions:

1. Why did you colour it this way?

2. Do you remember the rule for this activity? [The researcher repeated the rule as given at the beginning of the activity]

3. Do you feel like you followed the rule in your picture? How?

\section{Procedure}

Most children were tested in a lab setting on a university campus; others were tested in a small, quiet room at a participating preschool or daycare. First, the video described above played. After the two speakers labelled each familiar or novel object, the researcher asked the child to endorse the label or labels provided. For example, on a novel object trial, the speaker might say, "Okay [name of child], what do you think is the right name for this toy? Rompet? Chisa? Or are both names okay? Chisa? Rompet? Or are both names okay?" Children were offered the opportunity to play segments of the video more than once if struggling to recall any of the labels.

The researcher recorded all of the children's responses then administered the TVIP to bilingual children, following the standard procedure for this assessment. ${ }^{1}$ The researcher then administered the PPVT, per manual instructions. Finally, the child was asked to participate in the Language Silhouette Activity.

\footnotetext{
${ }^{1}$ Initially, all children were assessed using the TVIP; however, almost all monolingual children failed to establish a basal set, and thus did not produce a standardized score. Therefore, the TVIP was used to assess bilingual children only.
} 
At the completion of this activity, children were thanked and given the opportunity to select a "thank you" gift from a prize box.

\section{Results}

\section{Children's willingness to accept both labels}

Ninety-eight children participated in this task; 40 children were in the ExposureMinus category, 42 were in the Exposure-Plus category, and 16 were SpanishEnglish Bilingual. An additional six children were excluded either because they were fluent in a second language other than Spanish $(n=5)$ or due to fussiness $(n=1)$.

Coding of children's responses was as follows: children received

- a score of 2 if they endorsed both the English label and the Spanish label for the two novel objects,

- a score of 1 if they endorsed both the English label and the Spanish label for only one novel object, or

- a score of 0 if they endorsed neither of the two novel objects with the Spanish and English label (i.e., they selected either the Spanish or English label on both trials).

Mean response scores were 1.0 ( $\mathrm{SD}=.82)$ for the Exposure-Minus, 1.5 ( $\mathrm{SD}=$ $.74)$ for the Exposure-Plus and 1.56 $(\mathrm{SD}=.74)$ for the Bilingual group.

In the case that children endorsed only a single label (either the Spanish label or the English label, but not both), the English label (i.e., wibber or rompet) was most frequently (73.3\% of the time) the label of choice.

A series of $2 \times 3$ Chi-square tests were used to compare each of the three exposure categories; for each Chi-Square test, the number of children who scored 0,1 , or 2 , was compared across two exposure categories. Because each child's data was used in two comparisons, a $p$ value of .025 was used to correct for the multiple comparisons. With the correction, there was a significant difference between Exposure-Minus and Exposure-Plus, $\chi^{2}(2, N=82)=8.52$, $p=.01$. The difference between Bilingual and Exposure-Minus approached significance, $\chi^{2}(2, N=56)=5.7, p=.057$. There was no statistical difference between Bilingual and Exposure-Plus, $\chi^{2}(2, N=58)=1.09, p=.58$. A graph of the percentages of each score type (across conditions) can be seen in Figure 1.

A multinomial logistic regression was implemented in order to assess whether an age effect occurred on this task. Children were grouped by year (i.e., 4-year-old vs. 5-year-old vs. 6-year-old). No developmental effect was found. 


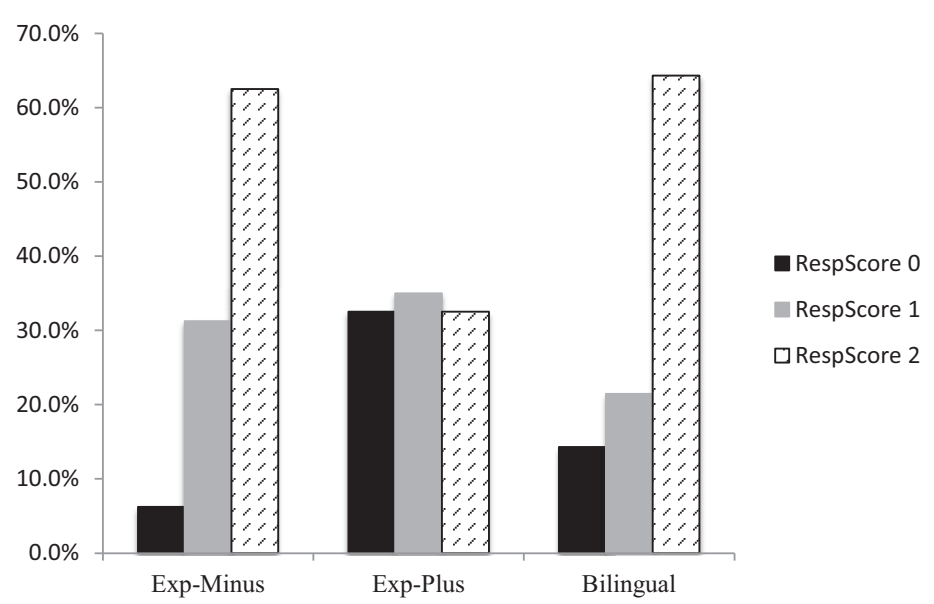

Figure 1

Percentage of children producing response scores of 0,1 or 2 for each language category.

To test the possibility that exposure to a third language might have a particularly strong influence on children's acceptance of labels across language, a post-hoc analysis comparing the responses of children with trilingual exposure against those without exposure to a third language ( $2 \times 3$ Chi-Square) was conducted. It revealed no statistical difference, $\chi^{2}(2, N=98)=3.64$, $p=.16$.

\section{Vocabulary assessments (PPVT and TVIP)}

Nine children failed to complete the PPVT, so were excluded from this analysis. The PPVT scores of the remaining 89 children correlated significantly, but negatively, with response scores $(r=-.282, p=.006)$. PPVT scores also correlated negatively with exposure $(r=-.246, p=.18)$. Children with higher PPVT scores were less likely than those with lower scores to accept labels across two languages, and they also had lower levels of exposure to Spanish. Mean PPVT scores were $116(\mathrm{SD}=12.9)$ for the Exposure-Minus, $111(\mathrm{SD}=$ $10.9)$ for the Exposure-Plus and $106(\mathrm{SD}=7.8)$ for the Bilingual group.

TVIP scores were not analyzed because only 14 children, across all three categories, established a standard score on the TVIP; 11 of these 14 children were Spanish-English bilingual children. ${ }^{2}$

\footnotetext{
${ }^{2}$ One possible reason for why even children with substantial exposure to Spanish (some of whom were reported to be hearing up to 30 hours of Spanish per week) per-
} 


\section{Language Silhouette}

Eighty-five children participated in this activity; an additional 13 children were excluded due to experimental error or missing data. Of these 85 children, 30 were from the Exposure-Minus category, 39 were from the Exposure-Plus category, and 16 were Bilingual.

No consistent patterns or colouring methods were evident, within or across groups, in children's drawings. Consequently, analyses focused on children's responses to the follow-up questions. Coding of these responses included, but was not limited to, explanations about the child's language dominance (that only small or large parts of the body were filled in with a colour because that represents the child's perceived proficiency in that language), the selected colour to represent each language, or some combination of these explanations. Evidence of language awareness was coded with a ' 1 '. A score of ' 0 ' represented no evidence of language awareness or a response that was otherwise incoherent (e.g., "I have a pink cat at home"). Four examples of coded responses to Language Silhouette questions can be found in Table 1; two of these examples represent a participant who received a score of 1 on this measure, two others represent a participant who received a score of 0 .

A series of $2 \times 2$ Chi-square tests were used to compare silhouette scores across the three exposure categories; for each Chi-Square test, the number of children who did and did not express language awareness was compared across two exposure categories. Because each child's data was used in two comparisons, a $p$ value of .025 was used. In Figure 2, children in the ExposureMinus category appeared to express language awareness in explanations of their colouring less frequently than those in the other categories, but the differences did not reach statistical significance; for Exposure-Minus vs. ExposurePlus, $\chi^{2}(1, N=69),=2.34, p=.13$, and for Exposure-Minus vs. Bilingual $\chi^{2}(1, N=46)=1.79, p=.18$. Children in the Exposure-Plus category did not differ from Bilingual children $\chi^{2}(1, N=55)=.64, p=.43$.

A binomial logistic regression was implemented in order to assess whether an age effect occurred on this task. Children were grouped by year (i.e., 4-yearold vs. 5-year-old vs. 6-year-old). No developmental effect was found.

\section{Child Language Questionnaire}

The Child Language Questionnaire also included questions that could provide insight into children's awareness of language. Select questions on this assess-

formed poorly on the TVIP is that a number of the images seem to be outdated. Indeed, some parents who were able to observe their children during the study indicated that their children had no experience with some of the items (e.g., a camcorder or Walkman), and so they were not surprised when their child was unable to identify it. 


\section{TABLE 1}

Examples of coded Language Silhouette question responses

\begin{tabular}{l|}
\hline \hline Language awareness score of 0 \\
\hline Example 1: \\
Q1. Because it looks like me
\end{tabular}

Language awareness score of 1

Example 1:

Q1. Because I speak one language [points to brown], two language [points to green], three language [points to blue]

Q2. Yes, because I followed the rule

Q2. You have to colour each for whatever amount of language you speak

Q3. By colouring

Q3. Because each colour that I spoke was how many languages I speak. Brown is English, because I speak it the most, green because I speak medium Spanish, and blue's French

Example 2:

Q1. Because those are my favourite colours

Q2. Yes, say each colour?.yeah, I don't remember the rest

Q3. No. Because I didn't say?one of the sounds I make?like I didn't talk

Example 2:

Q1. Because it would be beautiful

Q2. One colour for each language I speak

Q3. I only used purple for English and pink for Spanish. Oh, I changed it around, pink for English so there's a lot and little for purple because I only know a little bit of Spanish

Notes: Q1 = Why did you colour it this way?

Q2 = Do you remember the rule for this activity?

Q3 = Do you feel like you followed the rule in your picture? How?

ment were analyzed for evidence of language awareness. Other questions were not included because they did not apply to all participants or the content overlapped with the selected questions.

Eighty-five participants are included in this analysis; 13 children were excluded due to experimental error or missing data. Of the 85 children, 30 were from the Exposure-Minus category, 39 were from the Exposure-Plus Category, and 16 were Bilingual. Four questions from the questionnaire were selected, as they best addressed language awareness. The questions were as follow: 


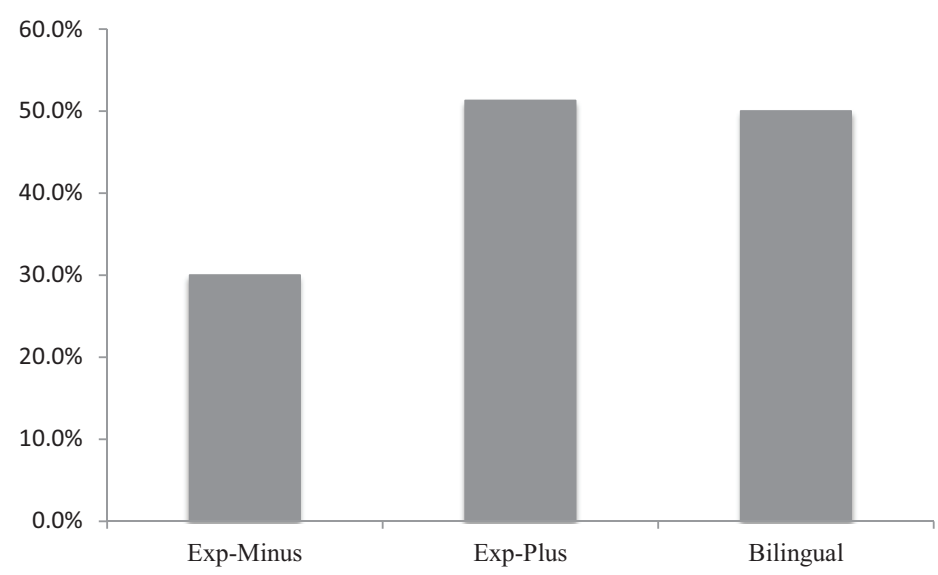

FIGURE 2

Percentage of children in each language category displaying language awareness on the Language Silhouette questions.

1. Which languages do you speak at home?

2. Which languages do you speak at school?

3. Which language is it easiest for you to say the things you want to say?

6a. Do you have a favourite language?

$6 \mathrm{~b}$. Which language is your favourite?

6c. Why is your favourite language?

A global score of 0 or 1 was assigned for Evidence of Language Awareness in responses to these four questions of the CLQ. A global score was implemented because children sometimes expressed evidence of awareness in one question but not in another, and qualitatively, some responses were more evident of awareness, while some responses were ambiguous single word responses. Two researchers independently coded question responses, and disagreements were resolved by discussion. Credit was given for responses that expressed an awareness of the child's language proficiency or the awareness that they are (or at some point were) learning a second language. Credit was given even in cases in which children provided single-word responses (e.g., to the question, "What language do you speak at home?", children often responded, "English") because any biases introduced by this decision would counter the hypothesis that minimally exposed monolingual children would be less likely to express language awareness. 


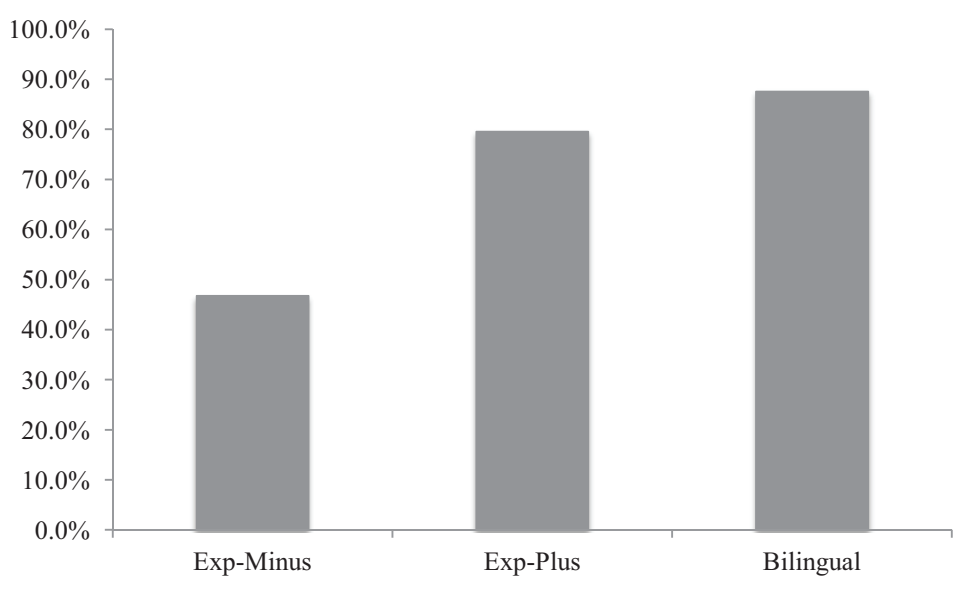

\section{FIGURE 3}

Percentage of children in each language category displaying evidence of language awareness on the Child Language Questionnaire.

A series of $2 \times 2$ Chi-square tests were used to compare each of the three exposure categories; for each Chi-Square test, the number of children who did and did not (Yes/No) express language awareness was compared across two exposure categories. Because each child's data was used in two comparisons, a $p$ value of .025 was used. As seen in Figure 3, children in the Exposure-Minus category were less likely to express language awareness when compared to either Exposure-Plus, $\chi^{2}(1, N=69)=6.67, p<.01$ or Bilingual children, $\chi^{2}(1, N=46)=5.69, p=.02$. As in the Language Silhouette Activity, children in the Exposure-Plus category did not differ from the Bilingual children, $\chi^{2}(1, N=55)=<.1, p=.75$.

Given the significant relationship between exposure and evidence of language awareness on the CLQ, we conducted a Chi-square analysis to assess the association between the CLQ global scores and children's labelling response scores. The analysis was conducted as a $2 \times 3$ table, with two levels of evidence of language awareness (Yes/No), and three levels of response score $(0,1,2)$. There was a significant relationship, $\chi^{2}(2, N=85)=5.17, p=.03$; children showing evidence of language awareness on the CLQ also exhibited higher response scores.

A binomial logistic regression was implemented in order to assess whether an age effect occurred on this task. Children were grouped by year (i.e., 4-yearold vs. 5-year-old vs. 6-year-old). An age effect was found, Wald $\chi^{2}(2, N=$ $92)=14.96, p=.001$. Older children were more successful on the task. 


\section{Discussion}

Our findings provide evidence that a modest amount of non-native language exposure promotes children's willingness to accept labels in a non-native language, and that it is not necessary to be proficient in the second language. Spanish-English bilingual children were more likely than those with minimal exposure to Spanish to endorse novel labels in both Spanish and English. Importantly, monolingual children with moderate exposure to Spanish did not differ from Bilinguals in their willingness to endorse labels in two languages. Indeed, whereas children with minimal exposure endorsed both labels only about one third of the time, both bilinguals and those with moderate exposure endorse both labels over $60 \%$ of the time.

The language awareness findings provide additional evidence that children with moderate exposure look quite different from those with minimal exposure. Children with greater exposure expressed evidence of language awareness on the global score of the Child Language Questionnaire, and did not differ from those fluent in Spanish. Importantly, the findings with this measure suggest that children who are not bilingual but have moderate exposure to a second language are similar to bilinguals in their language awareness. This finding supports the notion that there is a need to consider exposure as a factor when working with predominantly monolingual children.

The findings further suggest that language awareness is a predictor of willingness to accept labels in two languages. Although the data from our study do not permit such analyses, it would be interesting in future research to explore whether increased language awareness is, at least in part, the mechanism by which exposure affects willingness to accept labels in different languages.

The failure to find a clear pattern in the Language Silhouette results was disappointing. Although only 30\% of Exposure-Minus children demonstrated evidence of language awareness on the Silhouette measure, 50\% of Bilingual and $51 \%$ of Exposure-Plus did so. However, this difference did not achieve statistical significance. We incorporated the Language Silhouette measure recognizing that it was exploratory in nature. In the past, it had been used to assess language identity, and typically with older children. That the bilingual children did not achieve a success rate greater than $50 \%$ suggests that it is a difficult task. In that it requires that children treat their language(s) symbolically as colours, it is a more abstract task than the CLQ. Nonetheless, we believe that the measure has potential, and that it could be strengthened by making the instructions more concrete and by probing children's rationale for their drawings more systematically. It might also be useful to evaluate the measure with older children.

The effects of vocabulary in our study were inconsistent with past research, particularly Koenig and Woodward's (2012) finding that monolingual 
English-speaking toddlers with high vocabularies were more likely to endorse Dutch labels. Although we observed an association between PPVT and response scores, ours was negative. Given that PPVT scores also correlated negatively with exposure, we suspect that children with greater exposure to a nonEnglish language may have lower levels of exposure to English and, as a result, slightly lower PPVT scores. It should be noted, however, that PPVT scores were high and relatively similar across all three exposure categories, so the children with substantial exposure to non-English languages are not, from a practical perspective, disadvantaged. Moreover, because children did not consistently finish our Spanish vocabulary measure, we are unable to take into account children's Spanish vocabulary or total vocabulary across languages. The contrast with Koenig and Woodward's findings (2012) might be due to the much younger age of their participants-who at 24 months still would be rapidly acquiring new vocabulary items-or to a difference in vocabulary measure; Koenig and Woodward used the MacArthur-Bates Communicative Development Inventory (CDI).

In our study, we chose to focus on how Spanish exposure influences willingness to learn new words in Spanish. In future research, it would be valuable to determine whether children with exposure to languages other than Spanish would show a similar willingness to learn novel Spanish words.

The findings from this study show that a moderate amount of language exposure is associated with children's willingness to accept labels in both Spanish and English. Exposure is also associated with children's performance on a language awareness task that assesses children's ability to describe their language(s) and language use. The evidence that children who are exposed to a second language, but not fully bilingual, nonetheless show these advantages confirms that monolingual children are not homogeneous, and should not be considered as such. It may be beneficial to think about language exposure on a continuum, beginning with children with no exposure to a second language and increasing to children who are fluent in a second language.

Our evidence that children who are exposed to a second language, but not fully bilingual, nonetheless show advantages in willingness to learn and language awareness has educational implications. Parents considering enrolling their children in a dual-language immersion program might want to expose their children to a second language prior to entry into the program. NonEnglish exposure may help to promote willingness to accept, and therefore learn, vocabulary in a second language.

\section{References}

Akhtar, N., \& Menjivar, J.A. (2012). Cognitive and linguistic correlates of early exposure to more than one language. In J.B. Benson (Ed.), Advances in child develop- 
ment and behavior (Vol. 42, pp. 41-78). San Diego, CA: Elsevier Academic Press. doi:10.1016/B978-0-12-394388-0.00002-2

Akhtar, N., Mejivar, J.A., Hoicka, E., \& Sabbagh, M.A. (2012). Learning foreign labels from a foreign speaker: The role of (limited) exposure to a second language. Journal of Child Language, 39, 1135-1149. doi:10.1017/S0305000911000481

$\mathrm{Au}$, T.K., \& Glusman, M. (1990). The principle of mutual exclusivity in word learning: To honor or not to honor? Child Development, 61, 1474-1490. doi:10.1111/j. 1467-8624.1990.tb02876.x

Bialystok, E. (1988). Levels of bilingualism and levels of linguistic awareness. Developmental Psychology, 24, 560-567. doi:10.1037/0012-1649.24.4.560

Bialystok, E. (1999). Cognitive complexity and attentional control in the bilingual mind. Child Development, 70(3), 636-644. doi:10.1111/1467-8624.00046

Bialystok, E. (2001). Bilingualism in development: Language, literacy, and cognition. New York: Cambridge University Press.

Bialystok, E., \& Feng, X. (2009). Language proficiency and executive control in practive interference: Evidence from monolingual and bilingual children and adults. Brain and Language, 109, 93-100. doi:10.1016/j.bandl.2008.09.001

Bialystok, E., \& Majumder, S. (1998). The relationship between bilingualism and the development of cognitive processes in problem solving. Applied Psycholinguistics, 19, 69-85. doi:10.1017/S0142716400010584

Cummins, J. (1978). Bilingualism and the development of metalinguistic awareness. Journal of Cross-Cultural Psychology, 9, 131-149. doi:10.1177/002202217892001

Davidson, D., \& Tell, D. (2005). Monolingual and bilingual children's use of mutual exclusivity in the naming of whole objects. Journal of Experimental Child Psychology, 92, 25-45. doi:10.1016/j.jecp.2005.03.007

Dunn, L.M., \& Dunn, L.M. (1986). Test de Vocabulario Peabody. Circle Pines, MN: American Guidance Service.

Dunn, L.M., \& Dunn, L.M. (1997). Peabody Picture Vocabulary-III. Circle Pines, MN: American Guidance Service.

Fernandez, M. (2006). Bilingual preschoolers: Implications for the development of identity and self-concept. Journal of Early Childhood and Infant Psychology, 2, 5-16. $\mathrm{x}$

Koenig, M., \& Woodward, A. L. (2012). Toddlers learn words in a foreign language: The role of native vocabulary knowledge. Journal of Child Language, 39, 322-337. doi:10.1017/S0305000911000067

Krumm, H.J., \& Jenkins E.M. (2001). Kinder und ihre Sprachen-lebendige Mehrsprachigkeit: Sprachenportraits [Children and their language - living multililingualism: Language portraits]. Vienna: Wiener VerlagsWerkstatt für Interkulturelles Lernen und Deutsch als Fremdsprache [The Viennese Publishing Workshop for Intercultural Learning and German as a Foreign Language]. 
Martin, B. (2012). Coloured language: Identity perception of children in bilingual programmes. Language Awareness, 21, 33-56. doi:10.1080/09658416.2011.639888

Melo-Pfeifer, S. (2015). Multilingual awareness and heritage language education: Children's multimodal representations of their multilingualism. Language Awareness, 24, 197-215. doi:10.1080/09658416.2015.1072208

Sá, M.H.A.E., \& Melo, S. (2007). Online plurilingual interaction in the development of language awareness. Language Awareness, 16, 7-20. doi:10.2167/la356.0

Stewner-Manzanares, G. (1988). The Bilingual Education Act: Twenty years later. New Focus Series: Occasional Papers in Bilingual Education (1987-1989), no. 6. Silver Spring, MD: National Clearinghouse for Bilingual Education. Available at: ncela. ed.gov/files/rcd/BE021037/Fall88_6.pdf. 